\title{
Eyes on social norms: A field study on an honor system for newspaper sale
}

\author{
Thomas Brudermann ${ }^{*}$, Gregory Bartel ${ }^{2}$, Thomas Fenzl ${ }^{2} \&$ Sebastian Seebauer ${ }^{1}$
}

\author{
Affiliations \\ (1) University of Graz, Austria \\ (2) University of Klagenfurt, Austria
}

\section{*Corresponding author}

DI Dr. Thomas Brudermann

Mail: Thomas.Brudermann@uni-graz.at

Phone: +43 316 380-7336

Address: Merangasse 18/1, 8010 Graz, Austria

\begin{abstract}
Honor systems are a cheap and simple way for marketing low-price goods. These sale systems are dependent on the honesty of customers, and can only tolerate a certain share of free-riders. In an experimental field study we investigate a case where honesty has almost disappeared, namely an honor system for the sale of newspapers on weekends. In the chosen urban study area, only a minority of customers complies with payment norms. In this difficult setting, we tested the use of eye images and descriptive social norms as cues to improving payment morale over a period of 24 weeks. We find that interventions based on eye cues as well as normative appeals do not evoke a transition from low to high levels of honesty. However, our results suggest that such interventions might still have the potential to marginally increase mean payments, and therefore be economically profitable for operators of large-scale honor systems.
\end{abstract}

Keywords: honor system; social norms; eye images; newspaper sale; free-riding

\section{Important Note}

This is a preprint version of the following paper:

Brudermann T, Bartel G, Fenzl T \& Seebauer S (2014). Eyes on social norms: A field study on an honor system for newspaper sale. Theory and Decision, DOI: 10.1007/s11238-014-9460-1.

Original version: http://link.springer.com/article/10.1007/s11238-014-9460-1 


\section{Introduction}

An honor system is a form of sales concept which is mainly used for marketing low-price goods. In honor systems, consumers typically acquire a certain product on a self-service basis, and pay for it without any payment control, e.g. by inserting the required amount of money into a cash box available at the point of sale. Honor systems are a cheap and simple method of marketing goods, especially where the expected turnover is relatively low and does not justify employing a cashier, or using a sales machine.

Frequent applications of this honesty-based sales concept include the sale of candy or coffee in firm canteens, the self-picking of flowers, small-scale farmer-to-consumer direct marketing, or the sale of newspapers. Another related example is self-checkout cash desks at retail stores where consumers scan the barcodes of items themselves, and then pay with their bank or credit card.

As the term 'honor system' suggests, all these sales systems are dependent on the honesty of the customers. Usually, a certain share of free-riders can be tolerated, but too large a number will cause any honor system to collapse. Thus, the central challenge is to ensure high payment morale and to limit free-riding as much as possible despite the anonymous interaction between vendor and customer. At the same time, honor systems represent a nice opportunity for studying honest and dishonest behavior in the field. The question of how to reduce freeriding and how to increase honesty has been addressed by previous studies in a variety of settings, applying moral appeals, or 'eye images', i.e. photos of a pair of human eyes, as cues for social norms.

One straightforward approach is to withdraw the service, as soon as the payment levels fall under a certain threshold. This was done, for example, in a candy bar case studied by Haan and Kooreman (2002). In their study, involving medium and small-scale companies provided with candy bars, the consumers (i.e. employees of the respective companies) were informed that the service would be stopped if payments fell below a certain threshold. The threshold was set at $65 \%$, but this was not revealed to the consumers. Honesty levels under these circumstances were rather high, and only in 29 out of 166 companies was the service discontinued due to shortfalls in payments.

\subsection{Moral and social appeals}

Another approach is to use moral appeals. For example, in one case study on an honor system for newspaper sale, it was found that while moral reminders increased the amount of money given by those who actually paid, there was no increase in the number of people paying (Pruckner \& Sausgruber, 2013). In a study on honesty-based flower picking, the presence of internal moral norms was suggested as being an important predictor of payment levels, thus making it plausible that activating these norms would improve payment morale (Schlüter \& Vollan, 2011).

Appeals based on social norms seem to be a promising approach for increasing payments in honor systems as well. In experimental settings, the compliance of most people with social norms is conditional upon the compliance of others (Fehr, Fischbacher, \& Gächter, 2002; Fehr \& Gächter, 2002; Fischbacher, Gächter, \& Fehr, 2001). For the case of honor systems, this finding implies that most consumers would be willing to pay correctly, if they knew that 
others did so as well. Hence the challenge is to make norms of desired behavior more salient, for example by providing information on how other people behave in certain situations. Such attempts succeeded in a study on towel reuse conducted in US hotels (Goldstein, Cialdini, \& Griskevicius, 2008), and in a study on household energy conservation ${ }^{1}$ (Schultz, Nolan, Cialdini, Goldstein, \& Griskevicius, 2007). Participants in these studies were simply informed of other people's good conduct and this was sufficient for them to align their own behavior to the norm. Environmental cues also have the potential of communicating a certain normative standard. Keizer et al. (Keizer, Lindenberg, \& Steg, 2008) for instance showed that the presence of graffiti next to a no-graffiti sign increases the likelihood of littering at such a location. They suggested that the presence of graffiti indicated the violation of the no-graffitinorm, and led people to believe that it was normal or acceptable to disregard rules, and consequently other norms were more likely to be violated as well.

\subsection{Eye images}

More recently, a completely different approach has emerged: Haley \& Fessler (2005) initially suggested that the presence of pictures of human eyes positively affects pro-social behavior in experimental settings. This observation was confirmed in a quasi-field study conducted by Bateson et al. (2006). They found that university staff paid more for their coffee in a selfservice coffee-bar, when such 'eye images' were present.

Subsequent studies with eye images have since been extended to cover applications beyond honor systems. The aim is to improve honesty and pro-social behavior or to reduce delinquent behavior in anonymous settings. Ernest-Jones et al. (2011) successfully used eye images in order to reduce littering in a university canteen. In addition, combining the eye images with a written appeal not to litter was more effective than combining eye images with an unrelated message. In a field study at a bus stop, people waiting were more often willing to remove litter (placed there secretly by the experimenters), when eye images were present (Francey \& Bergmüller, 2012). Apart from that, eye images might also aid crime prevention. The presence of a large eye image at bicycle racks, in combination with a moral reminder ('cycle thieves we are watching you'), dramatically reduced thefts in those locations where it was used (Nettle, Nott, \& Bateson, 2012). However, since control locations experienced a dramatic increase of thefts, it seems that overall crime levels were not reduced, but merely that crime shifted to different locations.

However, recent experimental results call for a very careful interpretation of the effects observed. Fehr \& Schneider (2010) found zero effect when investigating the impact of 'eye cues' on cooperativeness in a trust game; and Raihani \& Bshary (2012) similarly found no effect of eye images on cooperative behavior in a dictator game carried out under truly anonymous conditions. On the other hand, a recent replication study by Nettle et al. (2013) confirmed the initial findings by Haley \& Fessler (2005), and clarified that while 'watching eyes' may increase the probability of donating something, they do not increase the mean donation in the dictator game setting.

\footnotetext{
${ }^{1}$ In the study mentioned here, households consumed less energy, when they learned that they were above average, and consumed more, when they learned that they were below average. An undesirable boomerang effect was successfully mitigated by introducing injunctive norms - i.e. approval or disapproval for those below or above the average energy consumption level.
} 
To sum up, the presence of eye images seems to increase cooperation levels and normcompliance in a variety of settings - but not in all settings. It is not yet clear from the literature in which kind of settings cues of being watched have the potential to increase honesty or pro-social behavior and in which not. An explanation for the efficacy of eye images as a subtle cue to being observed may be the essential role that eyes and eyebrows play, as has been pointed out by several studies investigating eye movement and gaze control during face learning and face recognition (Grüter, Grüter, \& Carbon, 2008; Henderson, Williams, \& Falk, 2005; Janik, Wellens, Goldberg, \& Dell'Osso, 1978; Walker-Smith, Gale, \& Findlay, 1977).

\subsection{Aim of the paper}

The aim of this paper is to investigate payment morale in a specific honor system, namely the 'silent sale' of newspapers in an urban region. The chosen study region represents a 'difficult case' in that relatively high levels of dishonesty prevail, i.e. payment morale here is particularly low when compared to other regions. Individual behavior in this setting is completely anonymous, so that customers need not fear retribution and cannot infer anything about norms by observing the actions of others. Under such circumstances, increasing the level of payment is not likely to be an easy task.

We aim to address this task, and state our research question as follows: Which cues are effective in increasing honesty in such a system - norm-based appeals, the presence of eye images, or both? The combination of descriptive norms and cues about being watched has, to the best of our knowledge, only been addressed marginally, although such a combination seems promising: Social norms may lose power when people feel unobserved. This can be counteracted to some extent by introducing specific 'cues' which increase the sense of being watched.

Furthermore, we are also interested in whether such cues are subject to a saturation/exhaustion effect. Does their effectiveness decreases over time? Can cues be 'turned on and off', so that the 'moral effect' vanishes when the cue is canceled, but reappears as soon as the cue is introduced again?

We have to keep in mind that this real-world setting involves behavior which is repeated on a regular basis for a long period, and which is habitual to a certain degree. It is rather difficult to isolate this decision making process, i.e. whether to pay correctly or not for the newspaper, from the familiar context it usually is embedded in. We therefore consider a field study as the best approach for addressing our research questions. Previous field studies with eye cues have to date mainly been conducted in university settings (i.e. institute kitchen, university canteen, campus) and have involved academic staff and students. Thus, studies of the general population tend to be underrepresented in this domain. This means that the overall validity of the results from such studies if often open to challenge (Levitt \& List, 2007; Thøgersen, 2008). In contrast, our study helps rectify the situation somewhat by dealing with a population outside the world of students and academic staff. As a result, our approach offers a higher degree of external validity, but also less rigor regarding experimental conditions.

The remainder of the paper is structured as follows: In section 2, our study design and the chosen methods are presented. Section 3 summarizes the results of statistical analysis. In 
section 4, we discuss the limitations to and implications of our study. A concluding section completes the paper.

\section{Material and methods}

\subsection{Study case: Silent newspaper sale}

In Austria, weekend issues of daily newspapers are sold through an honor system named 'silent newspaper sale'. Transparent plastic bags are filled with several copies of one newspaper. The bags are distributed in neighborhoods across Austria, together with a padlocked cash box, which is labeled with the price for one copy. Such 'sales bags' can be found in virtually every Austrian municipality and in nearly every neighborhood; they are usually mounted on road signs or street lamps. In Austria's capital Vienna, six different weekend newspapers are sold citywide in this manner. The sales bags are usually mounted on Friday and filled with copies on Saturday or Sunday morning. The sales bags and cash boxes are collected on Sunday evening.

Readers may take a copy from the bag on a self-service basis, and pay by inserting the respective amount of money into the cash box. There is no payment control: Copies are provided in freely accessible plastic bags and inserting money is not a prerequisite for getting a newspaper. Hence, readers find themselves in a situation with the following alternatives: Taking a copy of the newspaper and paying correctly (or too much), or taking a copy without paying correctly (i.e. nothing or too little).

While, strictly speaking, the latter alternative is theft, there are practically no negative consequences as a result of such behavior. Furthermore, inserting coins can easily be faked, and as long as there is already is some money in the cash box, conviction of theft is only a very remote possibility. On the assumption that individuals are rational, utility maximizing agents, one would not expect payment morale in such a setting to be exemplary. In practice, only a minority of people pay a proper price (if at all) for their newspaper. Stealing newspapers generally seems to be seen as a peccadillo, and is even regarded as socially acceptable to some extent. Distributers have found regional differences in payment morale, e.g. it is higher in rural areas and, interestingly, in neighborhoods inhabited by people with lower income ${ }^{2}$. In metropolitan and large urban areas, in particular, many readers do not pay, or they pay way too little.

Although such an honor system obviously has disadvantages, the distributers stick to it for a number of reasons. Traditional newspapers in Austria are in heavy competition with a growing number of free newspapers, and circulation and media penetration can be increased via the concept of silent sale. Moreover, most shops in Austria are closed on Sundays and holidays; therefore it would be difficult for non-subscribers to obtain a copy elsewhere. Offering newspaper copies on a self-service basis is also part of the marketing strategy of most Austrian newspapers, since publicly available sales bags increase the visibility of the

\footnotetext{
${ }^{2}$ This observation is in line with studies conducted by Piff et al. (2012), which suggest that unethical behaviour increases with social class.
} 
respective newspaper. Last but not least, the covers of the sales bags not only serve as advertising space for the newspaper, they can also be booked by third parties.

\subsection{Study design}

We conducted the study in a neighborhood in the city of Vienna, Austria, from June to December 2011, in cooperation with a distribution company engaged in the silent sale of newspapers. The newspapers involved were three national quality newspapers selling for a regular price of $€ 1$ to $€ 2$. To ensure anonymity, we refrain from naming either the newspapers or the distribution company.

The neighborhood where the study was conducted is predominantly inhabited by middle and upper class people, and, according to the distributing company, characterized by especially weak payment morale. Four study areas were set up, with 15 sales bags each, i.e. 5 sales bags of each of the newspapers involved. Each sales bag was filled with eight copies of one newspaper on Saturday or Sunday morning ${ }^{3}$. The sales bags were placed in the same location every weekend in rather calm streets with relatively low frequency of pedestrians. Naturally, it was not possible to avoid the presence of additional sales bags in the study area - that is, to avoid the presence of other newspapers sold by different distributors.

The study areas were randomly assigned to one out of four types of intervention (i.e. forms of experimental manipulation). In our case, three experimental interventions and one control intervention were used. The areas did not overlap. For reasons of organization and logistics, it was not possible to assign single sales bags to different interventions.

The sales bags in the study areas were subject to experimental intervention as follows (see Figure 1):

(1) Area 1, eyes: Use of a life-size image of human eyes, as found in previous studies (Bateson et al., 2006; Ernest-Jones et al., 2011). The particular image was chosen due to its effectiveness in the prior studies, and its rather neutral eye expression. Although a more alarmed eye image was the most effective in Bateson et al.'s original study, we refrained from using it in order not to 'scare' potential readers away.

(2) Area 2, norm: A sheet containing a descriptive social norm, stating "The majority of our readers pay for their weekend newspaper." Descriptive social norms can effectively increase cooperation, especially if they point out commonalities between the subject addressed and 'the others' (Goldstein et al., 2008). In our study, other readers of the same newspaper served as the reference group, hence the commonality was defined as 'reading the same newspaper'.

(3) Area 3, eyes plus norm: A combination of (1) and (2): The text used emphasized that paying correctly was the prevalent social norm and the eye image acts as a simple cue to stimulating a feeling of being watched.

(4) Area 4, control: A blank white sheet (control condition) was used in order to avoid any confounding effects.

\footnotetext{
${ }^{3}$ The sample included one newspaper delivered on Saturday, and two newspapers delivered on Sunday morning.

${ }^{4}$ This statement does not hold true for silent sale customers in the study region. However, it is true that the majority of readers do pay, since the newspapers in question are also sold in other regions, and via different channels that are less susceptible to theft.
} 
Usually, advertising messages are attached to the flap covers of the sales bags. We replaced these with our three experimental forms of intervention, and with the blank white sheet in the control condition ${ }^{5}$.

Fig. 1: Forms of intervention applied in the study (facsimile)

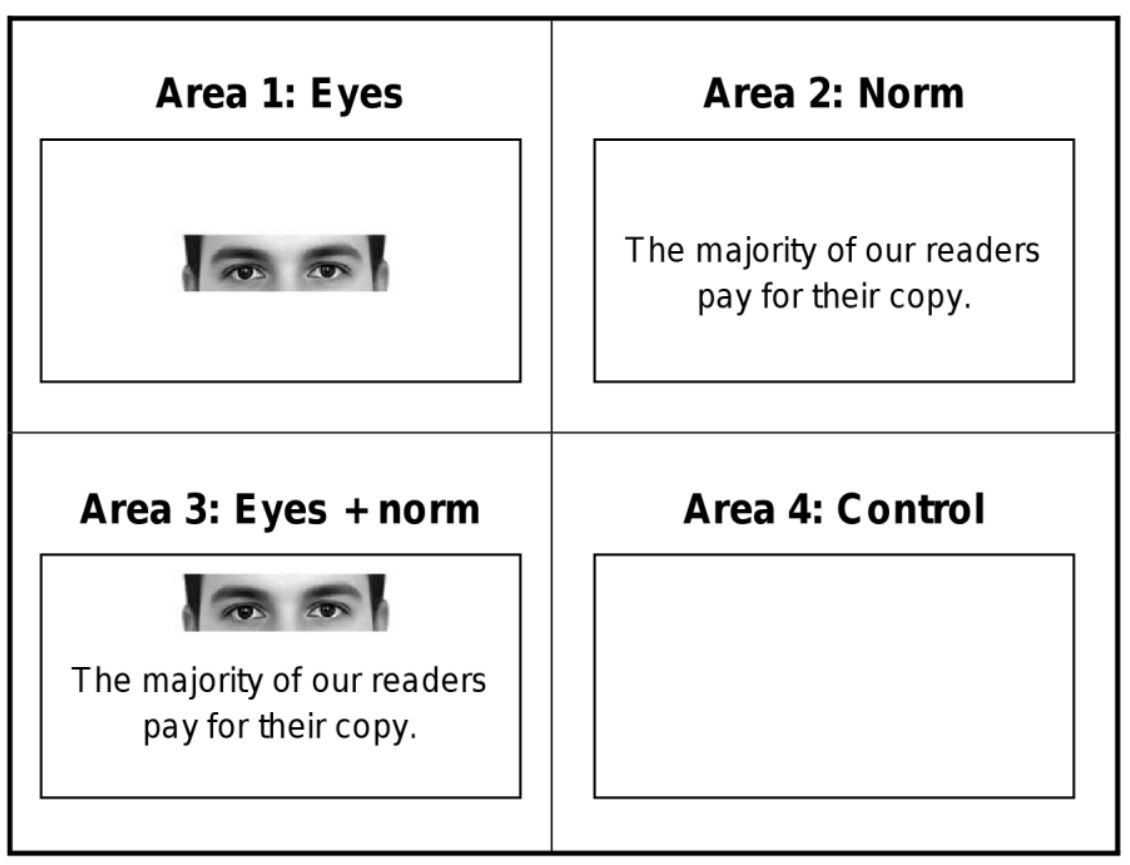

Table 1. Study design. The three forms of intervention (eye image, normative text, combination of eye and norm) were applied in stages II, IV and VI. Stages I, III and V served as control periods, where the interventions were replaced by a blank white sheet.

\begin{tabular}{lcccccc} 
Stage & I & II & III & IV & V & VI \\
Calendar week & $24-27$ & $31-34$ & $35-38$ & $39-42$ & $43-46$ & $47-50$ \\
\hline Area 1 & Control & Eyes & Control & Eyes & Control & Eyes \\
\hline Area 2 & Control & Norm & Control & Norm & Control & Norm \\
\hline Area 3 & Control & Eyes + Norm & Control & Eyes + Norm & Control & Eyes + Norm \\
\hline Area 4 & Control & Control & Control & Control & Control & Control \\
\hline
\end{tabular}

\footnotetext{
${ }^{5}$ Whether the experimental manipulation was in fact perceived was not explicitly verified for two reasons: First, 'eye intervention' must not necessarily be perceived consciously to be effective. Prior studies using subtle manipulation such as eye images have also foregone such verification or have found that the eye images were not consciously perceived. Second, observing customers during purchase, or interviewing them afterwards, would have been difficult technically, since often only 4-5 newspaper copies are taken from one sales bag in a time span of 12 hours or more.
} 
The cash boxes attached to the sales bags were all labeled with the price for one copy, as is the case for normal sales bags outside the study. The price label, e.g. ' $€ 2$ ', can be considered as a prescriptive norm meaning 'please pay $€ 2$ for taking one copy'.

The study was conducted over 24 weeks and was divided into six stages (see Table 1: study design), each lasting for four weeks. Following an alternating scheme, a four week control stage was always followed by a four week intervention stage. For organizational reasons, there was a pause of three calendar weeks between stages I and II. Hence we collected 60 data points per group and stage, totaling 1,440 observations for the entire study.

It needs to be noted that although the study was conducted over the course of several weeks, it does not constitute a true longitudinal design with repeated measures. In our study, the interventions simply target the individual customer, whereas a truly longitudinal design would require the same people to visit the same sales bag every week. Obviously, this cannot be assumed in our case since customers may not always frequent the same sales location, e.g. the newspapers may be sold out in a particular location, or the customer may change the dogwalking route, etc. In addition, random passersby can also come from other city districts. Moreover, for regular readers it is more practical to subscribe to the newspaper than to have to look for a sales bag every weekend that has not already been emptied by earlier customers.

The sales bags were re-collected every Sunday evening and the amount of money in each cash box as well as the number of unsold newspapers in each sales bag were counted. Hence the average payment per 'sold', newspaper, as well as the number of newspapers withdrawn can be calculated for every single sales bag.

In order to ensure proper data quality, we implemented a series of quality management measures. Once per intervention stage, randomly selected cash boxes were filled with marked coins in order to check for theft; i.e. missing marked coins after collection would clearly indicate theft. In our study, no indication of widespread theft was actually found. Moreover, inspectors regularly checked for correct implementation of the study design, i.e. correct location of sales bags, and correct intervention according to location and experimental stage. A unique ID assigned to each cash box and to each sales bag guaranteed that every sales bag was mounted at the same location every week. The intervention sheets containing the eye image and/or the normative message were also protected from the possible detrimental effects of poor weather by use of a transparent wrapping.

\section{Results}

\subsection{Descriptive results}

We analyze two indicators of payment morale: (i) the number of newspapers withdrawn per sales bag, and (ii) the payment per copy withdrawn from a sales bag. These two indicators have to be analyzed separately since they are interrelated, and may be affected by the interventions differently. For example, intervention may serve merely to deter free-riders, while paying customers continue to put the same amount in the cashbox as always in order to comply with a perceived social norm. In such a case, the number of withdrawn copies falls, while average payment per copy increases. On the other hand, if the intervention increases all 
customers' willingness to pay, the number of withdrawn copies remains unchanged, but payment per copy increases. Figure 2 and Figure 3 show box plots of these two indicators, in all 24 calendar weeks, and in all four study areas.

Fig. 2: Payments per copy over the period of the study, shown in box plots. Intervention stages are indicated by grey-colored boxes, control stages are indicated by white boxes. Outliers, i.e. values greater than $\mathrm{Q} 3+1.5^{*} \mathrm{IQR}$ but smaller than $\mathrm{Q} 3+3 * \mathrm{IQR}[\mathrm{Q} 3=$ Third quartile; IQR $=$ Interquartile range Q3-Q1], are indicated by a ring. Extreme outliers, i.e. values greater than Q3 + 3*IQR, are indicated by an asterisk.
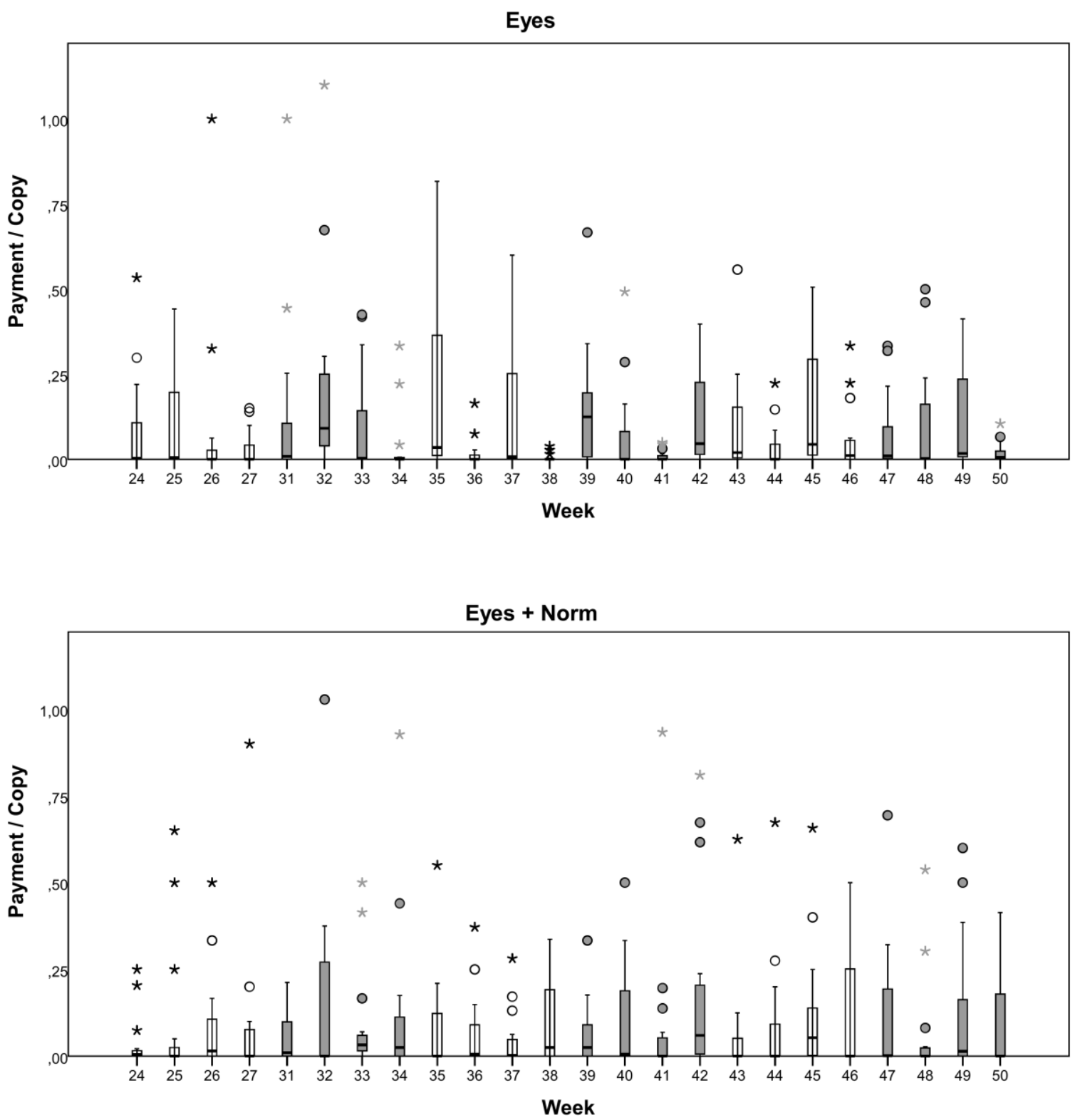
Fig. 2 continued
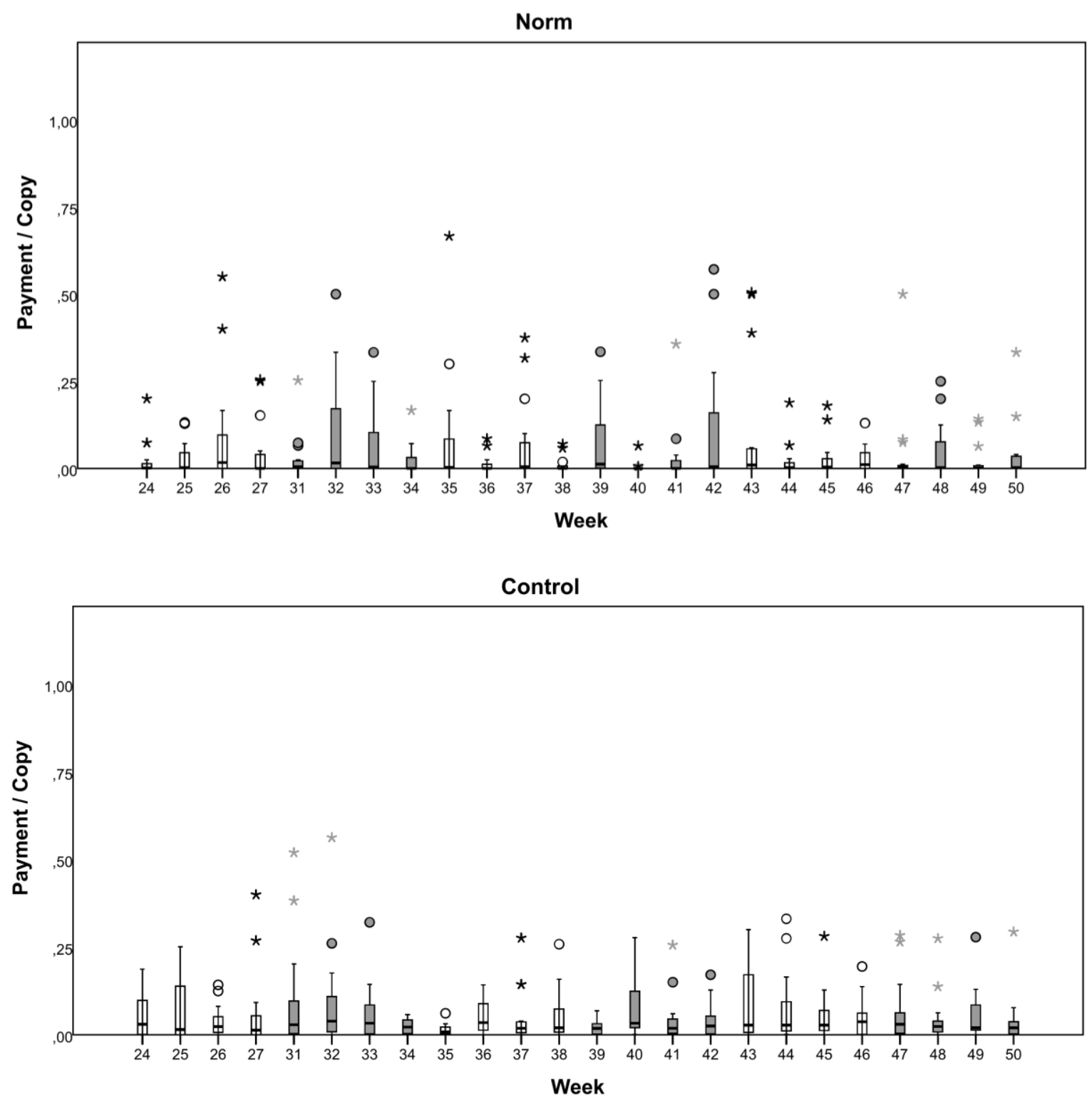

Overall, the data show high variability, both regarding substantial changes in the means of consecutive weeks, as well as in terms of high standard deviations. Numerous factors may contribute to this high level of variance: Weather conditions, outstanding public events, media interest, etc. In particular, the number of honest individuals can exert a significant influence on the sales bag average. The mean payment throughout the study of approximately $€ 0.1$ per newspaper is markedly low. If just one person pays the correct amount of $€ 2$ for their copy, the revenue from a fully emptied sales bag rises dramatically from $€ 0.8$ to $€ 2.7$, and hence the mean payment more than triples from $€ 0.1$ to $€ 0.34$ per copy from this sales bag. The high variability of the data obscures the effect of the interventions, thus rendering most of the following inferential statistical tests non-significant.

In order to deal with the high variability, we compare both indicators of payment morale across the 4-week stages instead of across single weeks. To do this, we increase the number of observations per group, and partially correct for unsystematic short-term variations between weeks. Number of copies withdrawn and payment per copy correlate weakly $(r=-.10, p<.05)$ : 
Unsurprisingly, the more copies are withdrawn, the lower the amount paid per copy. Although statistically significant due to the large sample size $(n=1434)$, the small correlation coefficient underlines that the two indicators are largely independent, supporting a separate discussion of observed intervention effects. Within all four areas and six stages, the correlations between the two indicators range from $\mathrm{r}=-.377$ to $\mathrm{r}=.326$. These correlations do not differ systematically between areas and stages, which precludes potential interaction effects between the two indicators of payment morale.

Fig. 3: Weekly number of withdrawn copies per sales bag over the period of the study, shown in box plots. Intervention stages are indicated by grey-colored boxes, control stages are indicated by white boxes. Outliers, i.e. values smaller than Q1 - 1.5*IQR but greater than Q1 - 3*IQR [Q1 = First quartile; IQR = Interquartile range Q3-Q1], are indicated by a ring. Extreme outliers, i.e. values smaller than $\mathrm{Q} 1-3 * \mathrm{IQR}$, are indicated by an asterisk.
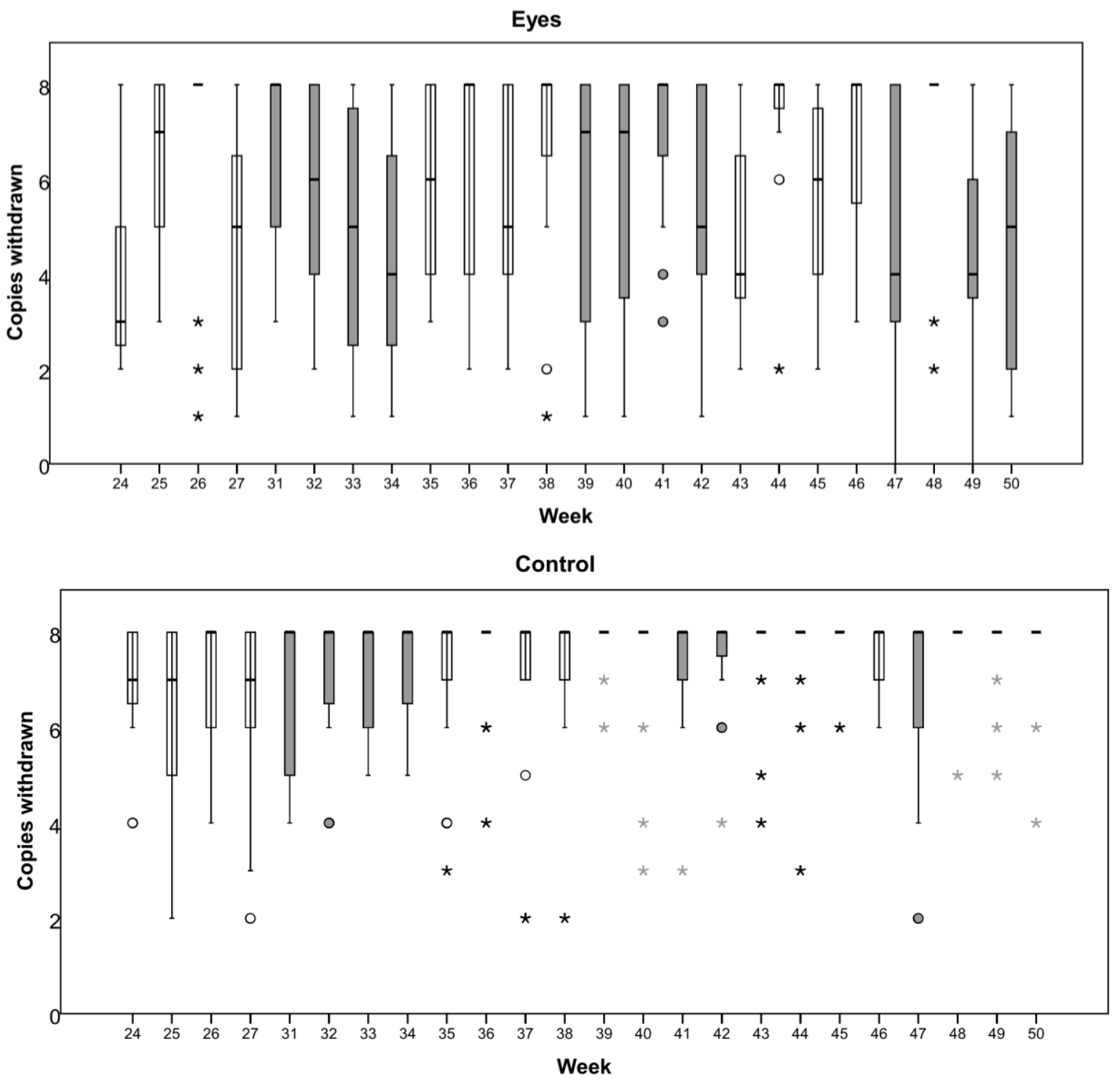
Fig. 3 continued

Eyes + Norms

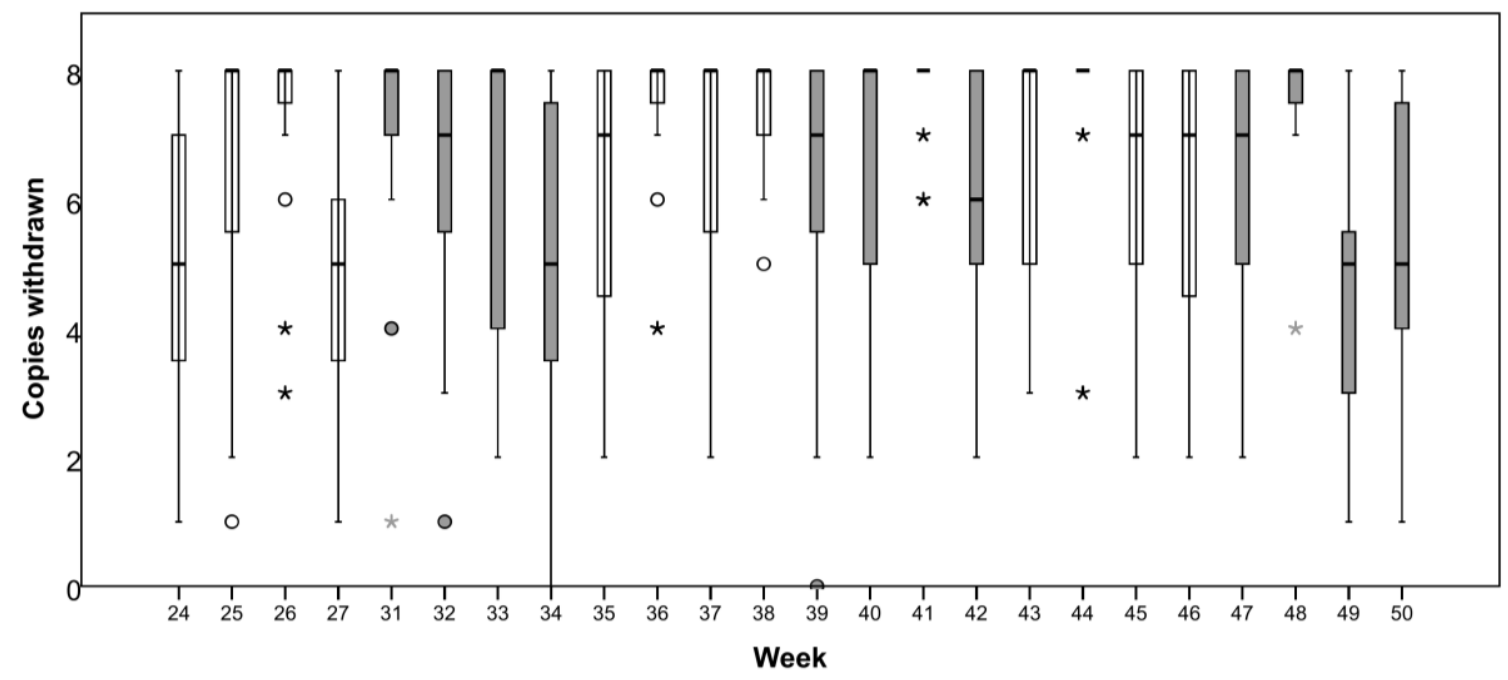

Norms

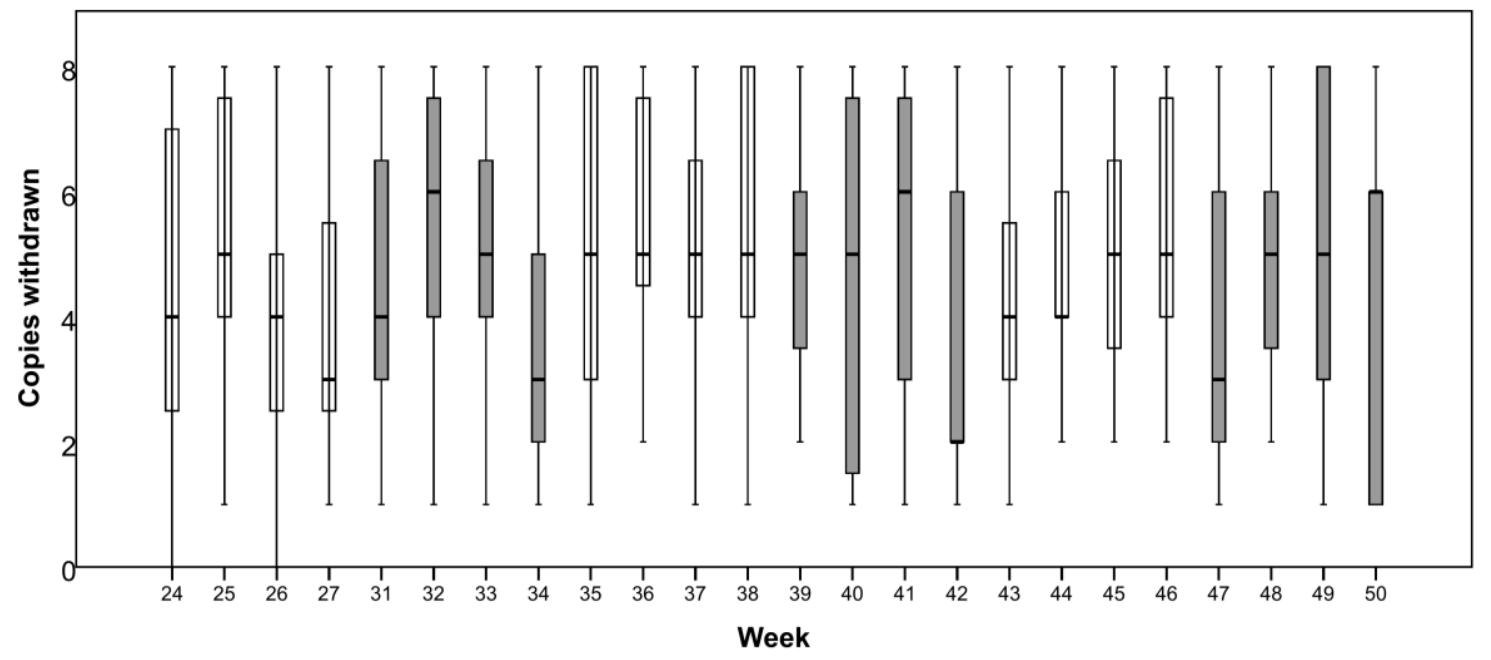

The control stages III and V followed directly upon the preceding intervention stages II and IV, making the control stages susceptible to spillover from the intervention stages. In the first week of the control stage, the norm prevailing in the last week of the intervention stage may still have been salient, so that customers continued to act more honestly, although the image or text cue was no longer present. In some areas payment morale remains rather high in the first week of stages III and V, and then declines over the remaining control weeks. We thus excluded the calendar weeks 35 and 43 from the analysis below. Hence, statistics for stages III and V refer to the remaining three weeks in each stage, i.e. to calendar weeks 36 to 38 and 44 to 46 respectively.

\subsection{Equivalence of study areas}

As mentioned in section 2.2, interventions were assigned to study areas instead of single sales bags. In order to directly compare the indicators of payment morale between areas, we need to establish that the baseline is equal across all four areas. Only if the number of withdrawn 
copies and the price paid per withdrawn copy do not differ across areas in control stage I (and ideally also in the later control stages III and V), may we assume that all areas had the same initial level of honesty.

Table 2. Withdrawn copies. Descriptive statistics for number of withdrawn copies per sales bag in all study areas and all stages (I-VI).

\begin{tabular}{llrrrrrr} 
Study & & I & II & III & IV & V & VI \\
Area & & Control & Intervention & Control & Intervention & Control & Intervention \\
\hline \multirow{4}{*}{ Eyes } & Mean & 5.35 & 5.37 & 6.20 & 5.98 & 6.33 & 5.28 \\
& SD & 2.46 & 2.36 & 2.29 & 2.39 & 2.10 & 2.67 \\
& $\mathrm{~N}$ & 60 & 60 & 45 & 60 & 45 & 60 \\
\hline Eyes & Mean & 5.83 & 6.08 & 7.07 & 6.48 & 6.62 & 5.78 \\
plus & SD & 2.44 & 2.34 & 1.57 & 2.04 & 1.97 & 2.15 \\
Norm & $\mathrm{N}$ & 60 & 60 & 45 & 60 & 45 & 60 \\
\hline \multirow{3}{*}{ Norm } & Mean & 4.40 & 4.78 & 5.40 & 4.58 & 5.04 & 4.63 \\
& SD & 2.34 & 2.34 & 2.15 & 2.51 & 1.91 & 2.44 \\
& $\mathrm{~N}$ & 60 & 60 & 45 & 60 & 45 & 60 \\
\hline \multirow{3}{*}{ Control } & Mean & 6.68 & 7.03 & 7.27 & 7.47 & 7.64 & 7.35 \\
& SD & 1.74 & 1.31 & 1.47 & 1.21 & .91 & 1.35 \\
& $\mathrm{~N}$ & 60 & 60 & 45 & 60 & 45 & 60 \\
\hline
\end{tabular}

Table 3. Payments. Descriptive statistics for cents paid per withdrawn copy in all study areas and all stages.

\begin{tabular}{llrrrrrr} 
Study & & I & II & III & IV & V & VI \\
Area & & Control & Intervention & Control & Intervention & Control & Intervention \\
\hline \multirow{3}{*}{ Eyes } & Mean & 8.08 & 12.19 & 5.40 & 8.80 & 8.53 & 8.13 \\
& SD & 16.89 & 22.62 & 12.54 & 14.03 & 13.64 & 13.50 \\
& $\mathrm{~N}$ & 60 & 60 & 45 & 60 & 45 & 58 \\
\hline Eyes & Mean & 7.88 & 12.65 & 7.03 & 11.61 & 11.37 & 10.28 \\
Plus & SD & 17.29 & 27.32 & 10.81 & 20.52 & 17.68 & 17.62 \\
Norm & $\mathrm{N}$ & 60 & 59 & 45 & 59 & 45 & 60 \\
\hline \multirow{3}{*}{ Norm } & Mean & 4.99 & 6.32 & 3.29 & 5.79 & 2.63 & 4.46 \\
& SD & 10.35 & 11.20 & 7.80 & 12.31 & 4.70 & 9.31 \\
& $\mathrm{~N}$ & 58 & 60 & 45 & 60 & 45 & 60 \\
\hline \multirow{3}{*}{ Control } & Mean & 5.62 & 6.94 & 5.27 & 4.59 & 6.07 & 5.19 \\
& SD & 8.07 & 11.80 & 6.65 & 6.33 & 8.05 & 7.73 \\
& $\mathrm{~N}$ & 60 & 60 & 45 & 60 & 45 & 60 \\
\hline
\end{tabular}


Table 2 shows that area 3 (Norm) had a lower, and area 4 (Control) a higher mean number of withdrawn copies than the other areas in all control stages. One-way ANOVAs ${ }^{6}$ show that these differences in means are statistically significant (stage $\mathrm{I}: \mathrm{F}=10.6, \mathrm{df}=3 / 236, \mathrm{p}<.001$; stage III: $\mathrm{F}=9.1, \mathrm{df}=3 / 176, \mathrm{p}<.001$; stage $\mathrm{V}: \mathrm{F}=16.2$, $\mathrm{df}=3 / 176 ; \mathrm{p}<.001$; in all cases, Levene's test of equality of error variances yields significant results with $\mathrm{p}<.05$ ). We find similar differences in payments per withdrawn copy within each control stage (Table 3), however, owing to the high variances in the data, these differences are not statistically significant in stages I and III (stage I: $\mathrm{F}=0.7, \mathrm{df}=3 / 234, \mathrm{p}=.51$; stage III: $\mathrm{F}=1.1, \mathrm{df}=3 / 176, \mathrm{p}=.35$; stage $\mathrm{V}$ : $\mathrm{F}=4.2, \mathrm{df}=3 / 176, \mathrm{p}=.006$; in all cases, Levene's test of equality of error variances yields significant results with $\mathrm{p}<.05$ ). Note that six observations throughout all areas and stages were removed from the data set, since not a single copy was withdrawn from the sales bag.

As the four study areas are non-equivalent regarding payment compliance prior to the interventions, absolute values of the indicators of payment morale may not be compared across interventions. Therefore, we conduct statistical analyses of absolute indicators separately for each study area.

However, to allow for comparisons between areas despite these different initial levels of honesty, we calculate scores relative to the baseline values: The number of withdrawn copies from a specific sales bag in a specific week is divided by the mean number of withdrawn copies from this particular sales bag during the baseline stage I (week 24 to 27). Thus, the relative scores reported in Table 4 reflect the average positive or negative deviation from the initial level of withdrawn copies, given in percent. Relative scores for cents paid per withdrawn copy are calculated similarly (Table 5). Note that some observations in the cents paid per withdrawn copy are missing, since no payments were made in particular bags during the entire baseline stage, thus prohibiting calculation of a relative change to a zero reference. Throughout, high variance in relative scores can be observed, especially with cents paid per copy, as small absolute changes from the baseline score may result in huge relative differences, e.g. when comparing an intervention value of 10 cents/copy to a baseline value of 0.03 cents/copy. This high variance precludes almost any statistically significant results.

\subsection{Impacts on payment morale}

Comparing the absolute indicators of payment morale across stages within each study area, one-way ANOVAs predominantly show non-significant or inconclusive results. The absolute number of withdrawn copies does not vary between stages in the 'eyes' area $(\mathrm{F}=2.0$, $\mathrm{df}=5 / 324, \mathrm{p}=.07)$ and the 'norm' group $(\mathrm{F}=1.2, \mathrm{df}=5 / 324, \mathrm{p}=.30$; in both cases, Levene's test indicates homogenous variances). In contrast, one-way ANOVAs for the 'eyes+norm' area $(\mathrm{F}=2.8, \mathrm{df}=5 / 324, \mathrm{p}=.02)$ and the 'control' area return significant results $(\mathrm{F}=3.4, \mathrm{df}=5 / 324$, $\mathrm{p}=.005$; in both cases, Levene's test shows heterogeneous variances, $\mathrm{p}<.001$ ). Post-hoc tests with two-sided Dunnett tests for homogenous subsets show that the absolute number of newspapers withdrawn is significantly higher in stage III than in stages I and VI within the

\footnotetext{
${ }^{6}$ As each of the cells in Tables 2 and 3 represents between 45 and 60 observations, it can be argued on the basis of the central limit theorem that data are normally distributed. According to Bortz (1989), one-way ANOVAs are robust even when homogeneous variances are absent, as long as the compared groups are of equal size and contain at least 10 observations. This applies similarly to the other ANOVAs conducted. Moreover, in all cases non-parametric Kruskal-Wallis tests yielded similar results.
} 
'eyes+norm' area, and that the number of newspapers withdrawn is significantly higher in stage V than in stage I within the 'control' area. However, it also has to be noted that all study areas show peaks in the number of withdrawn copies in stages III and V. Obviously, with respect to the control area, this seems to be a seasonal fluctuation which cannot be attributed to our intervention, since by definition, none was present.

Regarding absolute payments per withdrawn copy (Table 3), differences in the means between stages are not significant within any area ('eyes': $F=1.0, \mathrm{df}=5 / 322, \mathrm{p}=.44$; 'eyes+norm': $\mathrm{F}=0.7, \mathrm{df}=5 / 322, \mathrm{p}=.63$; 'norm': $\mathrm{F}=1.1, \mathrm{df}=5 / 322, \mathrm{p}=.38$; 'control': $\mathrm{F}=0.6$, $\mathrm{df}=5 / 324, \mathrm{p}=.74$; Levene's test shows heterogeneous variances only in 'norm', $p=.003$ ). Still, we observe increases in mean payments from stage I to II as well as from stage III to IV in the two experimental areas 'eyes' and 'eyes+norm'. In the experimental area 'norm' we observe an increase in every experimental stage, when compared to the preceding control stage.

However, small absolute intervention effects may emerge as more substantial when compared relative to the baseline levels of payment compliance. We find positive means in the relative scores throughout all stages and areas, indicating an overall relative increase both in newspaper demand (number of withdrawn copies, Table 4) and payment morale (cents paid per withdrawn copy, Table 5) ${ }^{7}$. Relative scores can be compared across stages within each area, similar to the absolute indicators. In addition, relative scores allow comparison across areas within each stage, as the standardization to the respective baseline values corrects for the lacking absolute equivalence between study areas during the control stages. Note that the following one-way ANOVAs of relative scores cannot include stage I, since this stage provides the baseline values the relative scores are standardized to. We reduce the significance level of in total 18 ANOVAs to $\mathrm{p}<.003$ using a Bonferroni correction.

Comparing relative scores across stages within each study area, as with the absolute indicators above, we do not find any significant mean differences, neither in the relative score for withdrawn copies ('eyes': $\mathrm{F}=2.3, \mathrm{df}=4 / 265, \mathrm{p}=.06$; 'eyes+norm': $\mathrm{F}=2.5, \mathrm{df}=4 / 265, \mathrm{p}=.05$; 'norm': $\mathrm{F}=2.3, \mathrm{df}=4 / 265, \mathrm{p}=.06$; 'control': $\mathrm{F}=2.1, \mathrm{df}=4 / 265, \mathrm{p}=.08$; Levene's test indicates homogenous variances) nor in the relative score of payment per withdrawn copy ('eyes': $\mathrm{F}=0.4, \mathrm{df}=4 / 229, \mathrm{p}=.82$; 'eyes+norm': $\mathrm{F}=0.3, \mathrm{df}=4 / 227, \mathrm{p}=.90 ;$ 'norm': $\mathrm{F}=0.3, \mathrm{df}=4 / 211$, $\mathrm{p}=.86$; 'control': $\mathrm{F}=0.1, \mathrm{df}=4 / 247, \mathrm{p}=.96$; Levene's test indicates homogenous variances).

Comparing relative scores across study areas within each stage, we observe a significant mean difference only in the relative score for withdrawn copies, in stage III, between the 'eyes+norm' and the 'control' area $(\mathrm{F}=3.3, \mathrm{df}=3 / 176, \mathrm{p}=.02 ;$ Levene's test shows heterogeneous variances, $\mathrm{p}<.001)$. Apart from this singular result, ANOVAs do not yield significant mean differences, neither in the relative score for withdrawn copies (stage II: $\mathrm{F}=0.8, \mathrm{df}=3 / 236, \mathrm{p}=.49$; stage $\mathrm{IV}: \mathrm{F}=0.7, \mathrm{df}=3 / 236, \mathrm{p}=.55$; stage $\mathrm{V}: \mathrm{F}=0.9$, df=3/176, $\mathrm{p}=.44$; stage VI: $\mathrm{F}=0.6, \mathrm{df}=3 / 236, \mathrm{p}=.61$; Levene's test shows heterogeneous variances in all stages, $\mathrm{p}<.001$ ) nor in the relative score of payment per withdrawn copy (stage II: $\mathrm{F}=1.5, \mathrm{df}=3 / 203$, $\mathrm{p}=.21$; stage III: $\mathrm{F}=0.8, \mathrm{df}=3 / 152, \mathrm{p}=.51$; stage stage $\mathrm{IV}: \mathrm{F}=1.6, \mathrm{df}=3 / 203, \mathrm{p}=.19$; stage $\mathrm{V}$ :

\footnotetext{
${ }^{7}$ Note that the relatively high percental deviations in the experimental condition 'Eyes' are caused by single sales bags with particularly low payment levels in the baseline stage. In such cases, moderate absolute increases (e.g. from 1 cent to 10 cents per copy) imply a dramatic relative increase (e.g. by 1000\%).
} 
$\mathrm{F}=0.8, \mathrm{df}=3 / 152, \mathrm{p}=.48$; stage $\mathrm{VI}: \mathrm{F}=0.8, \mathrm{df}=3 / 204, \mathrm{p}=.47$; Levene's test shows heterogeneous variances in all stages except stage III, $\mathrm{p}<.05$ ).

Table 4. Withdrawn copies, relative scores. Descriptive statistics for number of withdrawn copies per sales bag in all study areas and stages II-VI, in average percental deviation from the baseline stage I.

\begin{tabular}{|c|c|c|c|c|c|c|}
\hline Study & & & III & & V & \\
\hline Area & & Intervention & Control & Intervention & Control & Intervention \\
\hline \multirow{3}{*}{ Eyes } & Mean & 3.00 & 16.71 & 14.11 & 25.73 & 0.23 \\
\hline & $\mathrm{SD}$ & 47.43 & 38.53 & 46.26 & 56.84 & 56.88 \\
\hline & $\mathrm{N}$ & 60 & 45 & 60 & 45 & 60 \\
\hline Eyes & Mean & 5.39 & 24.01 & 13.62 & 15.66 & 1.95 \\
\hline plus & $\mathrm{SD}$ & 42.44 & 33.19 & 41.39 & 37.72 & 42.81 \\
\hline Norm & $\mathrm{N}$ & 60 & 45 & 60 & 45 & 60 \\
\hline \multirow{3}{*}{ Norm } & Mean & 14.65 & 34.73 & 4.83 & 29.73 & 8.76 \\
\hline & $\mathrm{SD}$ & 58.04 & 62.82 & 46.80 & 75.69 & 62.87 \\
\hline & $\mathrm{N}$ & 60 & 45 & 60 & 45 & 60 \\
\hline \multirow{3}{*}{ Control } & Mean & 5.51 & 8.35 & 12.27 & 15.06 & 9.98 \\
\hline & SD & 17.90 & 20.15 & 18.79 & 14.60 & 18.25 \\
\hline & $\mathrm{N}$ & 60 & 45 & 60 & 45 & 60 \\
\hline
\end{tabular}

Table 5. Payments, relative scores. Descriptive statistics for cents paid per withdrawn copy in all study areas and stages II-VI, in average percental deviation from the baseline stage I.

\begin{tabular}{llrrrrr}
$\begin{array}{l}\text { Study } \\
\text { Area }\end{array}$ & & \multicolumn{1}{c}{$\begin{array}{c}\text { II } \\
\text { Intervention }\end{array}$} & $\begin{array}{c}\text { III } \\
\text { Control }\end{array}$ & $\begin{array}{c}\text { IV } \\
\text { Intervention }\end{array}$ & $\begin{array}{c}\text { V } \\
\text { Control }\end{array}$ & $\begin{array}{c}\text { VI } \\
\text { Intervention }\end{array}$ \\
\hline \multirow{3}{*}{ Eyes } & Mean & 1556.56 & -36.88 & 2818.36 & 2087.04 & 2187.69 \\
& SD & 7177.98 & 150.40 & 14044.41 & 12920.94 & 14781.57 \\
& $\mathrm{~N}$ & 52 & 39 & 52 & 39 & 52 \\
\hline Eyes & Mean & 492.44 & 187.55 & 416.58 & 399.62 & 454.63 \\
Plus & SD & 1601.54 & 1022.33 & 1465.57 & 1323.64 & 1741.38 \\
Norm & $\mathrm{N}$ & 51 & 39 & 51 & 39 & 52 \\
\hline \multirow{3}{*}{ Norm } & Mean & 111.16 & 68.31 & 340.73 & 101.46 & 261.46 \\
& SD & 465.75 & 547.22 & 2303.33 & 696.59 & 1482.91 \\
& $\mathrm{~N}$ & 48 & 36 & 48 & 36 & 48 \\
\hline \multirow{3}{*}{ Control } & Mean & 270.92 & 179.17 & 191.73 & 122.14 & 173.51 \\
& SD & 1462.90 & 945.01 & 876.96 & 541.70 & 799.80 \\
& $\mathrm{~N}$ & 56 & 42 & 56 & 42 & 56 \\
\hline
\end{tabular}

Although practically all mean differences of relative scores are not statistically significant, presumably because of high variances obscuring a rather weak intervention effect, we observe interesting shifts between intervention and control stages: During the control stages III and V, the relative deviation of the number of withdrawn copies from the baseline stage I seems to be 
higher than in the intervention stages II, IV and VI (in support of this observation, the ANOVAs within area/across stages are marginally significant with $\mathrm{p}<.10$ ). This effect is weakest in the control area, and strongest in the norm area. We may assume that the written descriptive norm kept potential thieves from taking an unpaid copy. In a similar vein, the relative deviation in cents paid per copy appears higher during the intervention stages. This effect is most pronounced in the eyes area, and less clear in the norm and control areas. We may assume that the presence of an eye image encouraged buyers to insert more money in the cashbox (or any money at all).

To get clarity on whether the non-results are not just caused by a lack of observations, we conducted a-posteriori power analyses (Cohen, 1988). Comparing absolute and relative indicators of payment morale across stages and study areas, we computed empirical effects and observed powers when performing one-way ANOVAs (see Tables 6a-6d) ${ }^{8}$.

According to the a-posteriori power analysis for impacts on copies withdrawn (Table 6a) the possibility to detect the small effects ( $f \approx .20)$ between stages within the areas ranges from (1$\beta)=43 \%$ (norm) to $91 \%$ (control). Hence, the assumption that the absolute number of withdrawn copies differs between stages in the 'eyes+norm' area $(1-\beta=84 \%)$ and the 'control' area $(1-\beta=91 \%)$ is rather likely, as indicated by the statistically significant results. The possibility to detect the very weak effects on payments (between $f=.10$ and $f=.13$, see Table $6 \mathrm{~b}$ ) is rather small and ranges from $(1-\beta)=20 \%$ (control) to $38 \%$ (norm). Although we did not observe any statistically significant differences in the absolute means of payments per withdrawn copy between stages within any area, results of the power analysis suggest that the assumption of no effects on payment morale is wrong with a rather high probability of $\beta=62$ to $80 \%$. These results clearly indicate that the interventions tested are likely to have very weak effects on payment morale, but these are obscured by the noisy data. Given the same preconditions, our setting could detect slightly larger, but still small effects of $f=.20$ within the areas between the different stages with a power of $80 \%$, according to one-way fixed-effects ANOVAs (number of groups $=6$, total sample size $=328, \alpha$-error prob $=.05$ ).

Furthermore, we compared the indicators for the relative changes of copies withdrawn between stages within each study area (Table 6c). The possibility to detect the small effects $(f \approx .2)$ between stages ranges from $(1-\beta)=63 \%$ (control) to $70 \%$ (eyes + norm). Although we did not observe any statistically significant differences in the relative changes of copies withdrawn between stages within any area, results of the power analysis suggest that the assumption of no effects is wrong with a probability of $\beta=30$ to $37 \%$. As for relative changes in payments (Table $6 \mathrm{~d})$, the possibility to detect the very weak effects $(\mathrm{f}<.10)$ ranges from $(1-$ $\beta)=8 \%$ (control) to $14 \%$ (eyes). Hence, an assumption that no effects exist in the relative changes of payments between stages within the areas based on the non-significant results found is wrong with very high probability of $\beta=86$ to $92 \%$. Again, these results suggest that the interventions tested could have had small effects on relative changes, but these are obscured by the noisy data.

\footnotetext{
${ }^{8}$ Cohen (1988) suggests a power level of $(1-\beta)>80 \%$ as a standard for a-priori power analyses.
} 
Table 6. A-posteriori power analyses following Cohen (1988) for impacts on copies withdrawn and payment. Effect size $f$ is computed with empirical $\eta^{2}$ using G-Power, error level $\alpha=5 \%$.

Table 6a. Impacts on copies withdrawn

\begin{tabular}{ccccc} 
& Eyes & Eyes plus Norm & Norm & Control \\
\hline$\eta^{2}$ & 0,03035 & 0,04206 & 0,01852 & 0,05047 \\
$(1-\beta)$ & 0,676 & 0,838 & 0,434 & 0,909 \\
$n$ & 330 & 330 & 330 & 330 \\
\hline$f$ & 0,1769 & 0,209 & 0,137 & 0,2305
\end{tabular}

Table 6b. Impacts on payments

\begin{tabular}{ccccc} 
& Eyes & Eyes plus Norm & Norm & Control \\
\hline$\eta^{2}$ & 0,01481 & 0,01058 & 0,01639 & 0,00844 \\
$(1-\beta)$ & 0,346 & 0,249 & 0,382 & 0,203 \\
$n$ & 328 & 328 & 328 & 330 \\
\hline$f$ & 0,1226 & 0,1034 & 0,1291 & 0,0923
\end{tabular}

Table 6c. Impacts on copies withdrawn, relative scores

\begin{tabular}{ccccc} 
& Eyes & Eyes plus Norm & Norm & Control \\
\hline$\eta^{2}$ & 0,03325 & 0,03569 & 0,03399 & 0,03123 \\
$(1-\beta)$ & 0,661 & 0,698 & 0,672 & 0,628 \\
$n$ & 270 & 270 & 270 & 270 \\
\hline$f$ & 0,185 & 0,192 & 0,186 & 0,18
\end{tabular}

Table 6d. Impacts on payments, relative scores

\begin{tabular}{ccccc} 
& Eyes & Eyes plus Norm & Norm & Control \\
\hline$\eta^{2}$ & 0,00657 & 0,00474 & 0,00623 & 0,00237 \\
$(1-\beta)$ & 0,13635 & 0,109 & 0,124 & 0,08 \\
$n$ & 233 & 232 & 216 & 252 \\
\hline$f$ & 0,081 & 0,069 & 0,079 & 0,049
\end{tabular}




\section{Discussion}

\subsection{Observed effects}

At this point we return to our main research question: In a system of wide-spread dishonesty, is it possible to increase payment morale by using cues to suggest being watched, and/or via the use of normative appeals? Our answer is ambivalent: First, such cues definitely do not evoke a transition from low to high levels of honesty. However, such interventions might still have the potential to marginally increase mean payments, and therefore be economically profitable for operators of large-scale honor systems. Starting from relatively low honesty levels, our interventions increased payments only below statistically significant level, mainly due to high variance in the data. Still, these increases, especially in the first intervention stage, tot up to $30 \%$ to $50 \%$ (i.e. 1.3 to 4.8 cents per copy). With regards to relative changes, the normative message performed better than the eye cues or the combined intervention. With regards to absolute changes, however, the picture is reversed, mainly as a result of the absolute payments being particularly low in the norm study area. Hence there is no single type of intervention which outperforms the others.

An important additional result is that the interventions had practically no effect on the number of withdrawn copies. We therefore assume that the decision on whether to get a copy or not is taken separately from the decision on how much to pay for it.

Most likely, the interventions tested only affect people who have a guilty conscience to some extent when paying incorrectly for a newspaper. Consequently, the absolute effects might be larger in settings with higher initial honesty levels. On the other hand, people who habitually 'steal' a newspaper would probably not turn into honest payers simply because eye images or a similar form of intervention is present. We clearly have to distinguish this kind of habitual peccadillo, involving small amounts of money, from ordinary crime such as, for example, bicycle theft.

We furthermore were interested in saturation/exhaustion effects, and in whether the interventions could be switched off or on without losing their effectiveness. Unfortunately we have no clear answer. Stages I-IV of our experimental design suggest an affirmative answer. However, while in the last intervention stage the norm-based intervention still exhibited an increase of 1.83 cents $(70 \%)$ in mean payments when compared to the preceding control stage, the eye-based interventions no longer showed an increase in payments. Consequently, one could hypothesize that the effect of eye cues fade out, for example, due to habituation, while a text form of intervention, which repeatedly points to prevailing norms, leads to the latter's internalization and hence has a sustaining effect. However, this idea is given no support in the data: As the average payments in control stages of the norm study area were on a particularly low level, and steadily decreased from control stage I to control stages III and $\mathrm{V}$, the large relative increases in the intervention stages (e.g. of $60 \%$ or $70 \%$ ) come as no big surprise. Moreover, mean payments in the norm area remained far below mean payments in the eye study areas throughout the entire study.

Note, that across study areas honesty levels were not any higher in the Advent and Christmas season, occurring in stage VI. Although probably around 50-60\% of inhabitants in our study area were Christians, religious norms appear to have had no effect on honesty levels. This 
contrasts with results found in a study by Malhotra (2010), where a 'Sunday effect' was reported, i.e. an increase in pro-social behavior when religious norms are salient.

\subsection{Limitations of the study}

We are aware that confounding factors often influence field study results, and that these are difficult to control for. For example, the majority of newspapers are usually withdrawn in the morning hours. The likelihood of stealing is likely to be larger in the evening - assuming there are still copies left, as potential readers might find it easier to grab a newspaper without having guilty feelings, since they know it will otherwise go to waste. The same might be true for stealing from a fully filled bag, where enough copies are left. Due to the nature of the study we do not know how full a stand was whenever a payment (or non-payment) occurred, and therefore we could not control for these factors. Moreover, we could not track individual payments, but aggregate payments at the level of sales bags. Theft of copies cannot be prevented and might even occur on a commercial scale, i.e. a single thief might steal several copies early in the morning in order to re-sell them - this could be a possible explanation for the three weeks with results close to zero in the 'Eyes' study area.

Weather might be considered as an additional potential confounder in our case. However, we could not attribute observed fluctuations in weekly results to meteorological data. Seasonal confounders do occur, but they affect all study areas in the same way. Unusual events such as natural hazards, political scandals, large sports events etc. might also influence payment morale in certain weeks - e.g. because different readers take copies, or due to higher withdrawals as a result of a sudden peak in interest in a certain topic. On the weekends with particular high or low average payments we checked the title pages of the newspapers involved but were not able to find any particularly unusual events for the respective weekends.

\subsection{Conclusions and implications for further research}

The study reported here represents a first attempt, via the use of simple cues, at redirecting a malfunctioning honor system towards one which exhibits a greater level of honesty. As we have seen, normative appeals and the use of cues to being watched might have the potential to trigger minor improvements in the setting investigated. Payment morale in honor systems seems manipulable to some extent, depending on the nature of the intervention applied. However, our low-key interventions failed to cause significant changes from high levels of dishonesty towards higher levels of honesty. In the case of newspaper honor systems, in particular, stealing appears to be socially acceptable to some degree. The prevalence of such an anti-social norm is an obvious barrier to the use of interventions which rely on pro-social norms, such as normative appeals or cues about being watched. Furthermore, in an individualistic society, one in which people are accustomed to getting many things for free, e.g. music, films, computer games, various online services, and even newspapers, the use of honor systems is never going to be easy.

The fact that our interventions only led to increases in honesty which remained below statistically significant levels can be explained in several ways. First, where people have become accustomed to avoiding full payment (often over quite a lengthy period), a change in payment habits is likely to take some time. Moreover, people are likely to get accustomed to 
specific eye cues, and these consequently lose their effectiveness. There is some support for this in the later stages of our field study. We found, for example, that increases in payments faded out in the study areas where eye cues were present. Additional studies are definitely necessary to gain deeper insight into these matters.

Finally, we do not know much about the ideal properties of eye images and normative appeals. We are also relatively ignorant concerning how different types of eye images, e.g. regarding race, gender or expression, may affect cooperative behavior. Neither do we know how different facial expressions affect honesty. The eye image we used represented a rather neutral expression. However, it has been demonstrated that more emotional images showing fear, anger or disgust, lead to stronger and more widespread activity in the brain (Ishai, Schmidt, \& Boesiger, 2005). Thus, it is not unlikely that different images may have diverse effects on levels of honesty. Eye and face recognition have been studied widely in recent years (Ishai et al., 2005; Jack, Caldara, \& Schyns, 2012; Kanwisher, McDermott, \& Chun, 1997; Keil, 2009; Meng, Cherian, Singal, \& Sinha, 2012). However; to the best of our knowledge, no brain study has yet been carried out on the effect of eye images on cooperative behavior, or on habituation to eye cues. Although neuroscientific evidence might be useful, whether an appropriate study design can be found for this particular issue at all, remains an open question. In an artificial decision making situation employing brain scanning (e.g. fMRI), the scanner is probably the most salient factor, and the impact of subtle cues may easily be lost. We also have to recall that non-neuroscienctific experimental studies by Fehr \& Schneider (2010) and Raihani \& Bshary (2012) failed to confirm the effectiveness of eye cues. While real-world settings usually address every-day behavior, or at least behavior that is repeated on a regular basis for a long period, such as getting coffee or buying a newspaper, laboratory settings often involve one-shot decisions in artificial and unfamiliar environments where the participant not necessarily cares about the outcome. This not only goes some way towards explaining weaknesses or inconsistencies in current research results, it also (unfortunately) makes it difficult to collect additional useful evidence.

\section{Acknowledgments}

We thank the involved distribution company for their support in implementing this study. Melissa Bateson generously granted permission to re-use one eye image from the original studies. We furthermore thank Jürgen Fleiss, Angelika Wolf and Manfred Füllsack for their valuable comments. Constructive suggestions provided by two anonymous reviewers substantially improved this paper. 


\section{References}

Bateson, M., Nettle, D., \& Roberts, G. (2006). Cues of being watched enhance cooperation in a real-world setting. Biology Letters, 2, 412-414.

Bortz, J. (1989). Statistik für Sozialwissenschaftler [Statistics for Social Scientists] (3rd ed.). Berlin-Heidelberg: Springer.

Cohen, J. (1988). Statistical power analysis for the behavioral sciences. Hillsdale, NJ: Erlbaum.

Ernest-Jones, M., Nettle, D., \& Bateson, M. (2011). Effects of eye images on everyday cooperative behavior: a field experiment. Evolution and Human Behavior, 2, 172-178.

Fehr, E., Fischbacher, U., \& Gächter, S. (2002). Strong Reciprocity, Human Cooperation and the Enforcement of Social Norms. Human Nature, 13, 1-25.

Fehr, E., \& Gächter, S. (2002). Altruistic punishment in humans. Nature, 415(10), 137-140.

Fehr, E., \& Schneider, F. (2010). Eyes are on us, but nobody cares: are eye cues relevant for strong reciprocity? Proceedings of The Royal Society B, 277(1686), 1315-23. doi:10.1098/rspb.2009.1900

Fischbacher, U., Gächter, S., \& Fehr, E. (2001). Are people conditionally cooperative? Evidence from a public goods experiment. Economics Letters, 71(3), 397-404.

Francey, D., \& Bergmüller, R. (2012). Images of eyes enhance investments in a real-life public good. PLOS One, 7(5), e37397. doi:10.1371/journal.pone.0037397

Goldstein, N. J., Cialdini, R. B., \& Griskevicius, V. (2008). A Room with a Viewpoint: Using Social Norms to Motivate Environmental Conservation in Hotels. Journal of Consumer Research, 35(3), 472-482. doi:10.1086/586910

Grüter, T., Grüter, M., \& Carbon, C.-C. (2008). Neural and genetic foundations of face recognition and prosopagnosia. Journal of Neuropsychology, 2, 79-97.

Haan, M., \& Kooreman, P. (2002). Free riding and the provision of candy bars. Journal of Public Economics, 83(2), 277-291. doi:10.1016/S0047-2727(00)00157-2

Haley, K. J., \& Fessler, D. M. T. (2005). Nobody's watching? Evolution and Human Behavior, 26(3), $245-256$. doi:10.1016/j.evolhumbehav.2005.01.002

Henderson, J. M., Williams, C. C., \& Falk, R. J. (2005). Eye movements are functional during face learning. Memory \& Cognition, 33, 98-106.

Ishai, A., Schmidt, C. F., \& Boesiger, P. (2005). Face perception is mediated by a distributed cortical network. Brain Research Bulletin, 67(1-2), 87-93. doi:10.1016/j.brainresbull.2005.05.027

Jack, R. E., Caldara, R., \& Schyns, P. G. (2012). Internal representations reveal cultural diversity in expectations of facial expressions of emotion. Journal of Experimental Psychology, 141(1), 19-25. doi: $10.1037 / \mathrm{a} 0023463$

Janik, S. W., Wellens, A. R., Goldberg, M. L., \& Dell'Osso, L. F. (1978). Eyes as the center of focus in the visual examination of human faces. Perceptual and Motor Skills, 47, 857-858.

Kanwisher, N., McDermott, J., \& Chun, M. M. (1997). The Fusiform Face Area: A Module in Human Extrastriate Cortex Specialized for Face Perception. The Journal of Neuroscience: The Official Journal of the Society for Neuroscience, 17(11), 4302-11.

Keil, M. S. (2009). “'I Look in Your Eyes, Honey””: Internal Face Features Induce Spatial Frequency Preference for Human Face Processing. PLOS Computational Biology, 5(3), e1000329. doi:10.1371/journal.pcbi.1000329

Keizer, K., Lindenberg, S., \& Steg, L. (2008). The Spreading of Disorder. Science, 322(5908), 1681-1685. doi:10.1126/science.1161405

Levitt, S. D., \& List, J. A. (2007). What Do Laboratory Experiments Measuring Social Preferences Reveal About the Real World? Journal of Economic Perspectives, 21(2), 153-174.

Malhotra, D. (2010). (When) are Religious People Nicer? Religious Salience and the "Sunday Effect" on ProSocial Behavior. Judgment and Decision Making, 5(2), 138-143.

Meng, M., Cherian, T., Singal, G., \& Sinha, P. (2012). Lateralization of face processing in the human brain. Proceedings of The Royal Society B, 279(1735), 2052-61. doi:10.1098/rspb.2011.1784 
Nettle, D., Harper, Z., Kidson, A., Stone, R., Penton-Voak, I. S., \& Bateson, M. (2013). The watching eyes effect in the Dictator Game: it's not how much you give, it's being seen to give something. Evolution and Human Behavior, 34(1), 35-40. doi:10.1016/j.evolhumbehav.2012.08.004

Nettle, D., Nott, K., \& Bateson, M. (2012). "Cycle thieves, we are watching you": impact of a simple signage intervention against bicycle theft. PLOS ONE, 7(12), e51738. doi:10.1371/journal.pone.0051738

Piff, P. K., Stancato, D. M., Côté, S., Mendoza-Denton, R., \& Keltner, D. (2012). Higher social class predicts increased unethical behavior. Proceedings of the National Academy of Sciences of the United States of America, 109(11), 4086-91. doi:10.1073/pnas.1118373109

Pruckner, G. J., \& Sausgruber, R. (2013). Honesty on the Streets: A Field Study on Newspaper Purchasing. Journal of the European Economic Association, 11(3), 661-679.

Raihani, N. J., \& Bshary, R. (2012). A positive effect of flowers rather than eye images in a large-scale, crosscultural dictator game. Proceedings of The Royal Society B, 279, 3556-3564. doi:10.1098/rspb.2012.0758

Schlüter, A., \& Vollan, B. (2011). Morals as an incentive? A field study on honour based flower picking. European Review of Agricultural Economics, 38(1), 79-97. doi:10.1093/erae/jbq045

Schultz, P. W., Nolan, J. M., Cialdini, R. B., Goldstein, N. J., \& Griskevicius, V. (2007). The constructive, destructive, and reconstructive power of social norms. Psychological Science, 18(5), 429-34. doi:10.1111/j.1467-9280.2007.01917.x

Thøgersen, J. (2008). Social norms and cooperation in real-life social dilemmas. Journal of Economic Psychology, 29(4), 458-472. doi:10.1016/j.joep.2007.12.004

Walker-Smith, G. J., Gale, A. G., \& Findlay, J. M. (1977). Eye movement strategies involved in face perception. Perception, 6(3), 313-326. 